\title{
Predicting and Understanding the Reactivity of
}

\section{Aza[60]fullerenes}

\author{
Yago García-Rodeja,†, Miquel Solàł and Israel Fernández $* \dagger$
}

$\dagger$ Departamento de Química Orgánica I, Facultad de Ciencias Químicas, Universidad Complutense de Madrid, 28040-Madrid, Spain. + Institut de Química Computacional i Catàlisi and Departament de Química, Universitat de Girona, Campus Montilivi, 17003-Girona (Spain).

\section{israel@quim.ucm.es}

RECEIVED DATE (to be automatically inserted after your manuscript is accepted if required according to the journal that you are submitting your paper to)

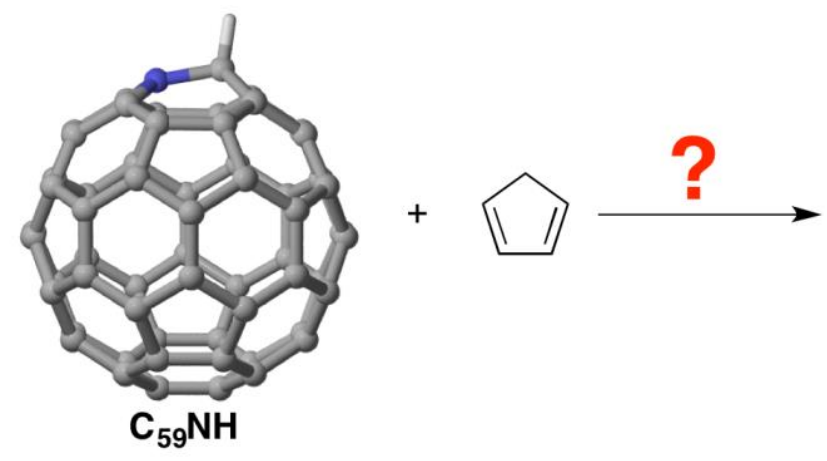

Abstract. The Diels-Alder reactivity of $\mathrm{C}_{59} \mathrm{NH}$ azafullerene has been explored computationally within the DFT framework. The regioselectivity of the process and the factors controlling the reduced reactivity of this system with respect to the parent $\mathrm{C}_{60}$ fullerene have been analysed in detail by using the activation strain model of reactivity in combination with and the energy decomposition analysis method. It is found that the presence of the nitrogen atom and the $\mathrm{CH}$ fragment in the fullerene strongly modifies the nature of the cage in the sense that significantly reduces the interaction between the 
deformed reactants along the entire reaction coordinate is remarkably reduced. This weaker interaction is mainly the result of weaker electrostatic and orbital interactions, the latter coming mainly from a less stabilizing $\pi($ diene $) \rightarrow \pi *($ fullerene $)$ interaction.

Due to their numerous potential applications in materials science and medicinal chemistry, fullerenes have become highly valuable molecular species. ${ }^{1}$ For this reason, it is not surprising that since the discovery of the parent $\mathrm{C}_{60}$-fullerene, ${ }^{2}$ a good number of synthetic methods have been developed to produce new fullerene derivatives with tuneable properties. ${ }^{3}$ In sharp contrast, the chemistry of heterofullerenes, i.e. fullerenes where carbon atoms of the cage are replaced by heteroatoms, is comparatively underdeveloped. This is mainly due to the difficulties associated with the preparation of such species. Indeed, most of the known heterofullerenes have only been prepared in the gas phase and detected by mass spectrometry. ${ }^{4}$

In this sense, azafullerenes constitute the only class of heterofullerenes which have been synthetized in macroscopic quantities. For instance, mono-azafullerenes $\mathrm{C}_{59} \mathrm{~N}$ and $\mathrm{C}_{69} \mathrm{~N}$ were isolated as the stable dimers $\left(\mathrm{C}_{59} \mathrm{~N}\right)_{2}$ and $\left(\mathrm{C}_{69} \mathrm{~N}\right)_{2}$, respectively, ${ }^{5}$ and very recently, also as their corresponding endohedral species $\left(\mathrm{H}_{2} \mathrm{O} @ \mathrm{C}_{59} \mathrm{~N}\right)_{2}$ and $\left(\mathrm{H}_{2} @ \mathrm{C}_{59} \mathrm{~N}\right)_{2 .}{ }^{6}$ In addition, the azafullerene derivatives $\mathrm{C}_{59} \mathrm{NH}$ and $\mathrm{C}_{59} \mathrm{NR}_{5}$ have been also obtained on a preparative scale. ${ }^{7,8}$ Because of their exceptional energy- and chargetransfer properties, $\mathrm{C}_{59} \mathrm{~N}$-based donor-acceptor dyads were employed in organic solar cells. ${ }^{7 \mathrm{c}, 9}$ In this context, it would be highly desirable to understand the factors which control the reactivity of these particular heterofullerenes to produce novel azafullerene derivatives that could be used in the design of more efficient solar cells.

In recent years, we have applied computational methods to predict and gain a deeper insight into the reactivity of fullerenes. ${ }^{10}$ In this regard, by means of the so-called Activation Strain Model (ASM) ${ }^{11}$ of reactivity in combination with the Energy Decomposition Analysis (EDA) method, ${ }^{12}$ we were very recently able to fully understand those factors governing the reactivity of fullerenes and related species. ${ }^{13}$ The insight gained has allowed us not only to understand the reactivity of these systems in a 
quantitative manner but also guide future experimental developments in the chemistry of fullerenes. Herein, we are interested in shedding more light into the reactivity of azafullerenes, which is almost completely unexplored to date. ${ }^{14}$ To this end, we have selected the Diels-Alder (DA) reaction between hydroazafullerene $\mathrm{C}_{59} \mathrm{NH}$ and cyclopentadiene $(\mathrm{CP})$.

Different to the parent $\mathrm{C}_{60}$-fullerene, where the preferred $[6,6]$-pyracylenic bonds are equivalent within the entire cage, $\mathrm{C}_{59} \mathrm{NH}$ exhibits sixteen chemically different $[6,6]$-bonds (Figure 1 ). In addition, two possible isomers per [6,6]-bond can be produced in the DA reaction. Our calculations indicate that the barrier and reaction energy differences between both approaches is negligible $(<0.5 \mathrm{kcal} / \mathrm{mol})$ and therefore, below we only refer to the most favored approach. ${ }^{15}$



Figure 1. [6,6]-bonds in $\mathrm{C}_{59} \mathrm{NH}$ considered in this study.

Similar to the reaction profile computed for $\mathrm{C}_{60},{ }^{13 \mathrm{a}}$ in all cases the reaction proceeds with the formation of an initial reactant complex (RC) which lies ca. $-7.0 \mathrm{kcal} / \mathrm{mol}$ below the separate reactants (see Table 1). The occurrence of this stable van de Waals complex highlights the importance of including dispersion corrections in the calculations involving fullerenes, as suggested previously by us. ${ }^{13,16}$ From this species, a concerted and relatively synchronous [4+2]-cycloaddition reaction takes place (see the corresponding fully optimized transition states in the Supplementary material) to produce the respective $[6,6]-$ cycloadduct in a highly exothermic reaction $\left(\Delta \mathrm{G}_{\mathrm{R}}\right.$ ca. $\left.-18 \mathrm{kcal} / \mathrm{mol}\right)$. 
Table 1. Computed relative energies (in $\mathrm{kcal} / \mathrm{mol}$, at the BP86-D3/TZ2P+//RI-BP86-D3/def2-SVP level) and free energies (within parentheses, at the RI-BP86-D3/def2-SVP level) for the Diels-Alder cycloaddition reactions between $\mathrm{CP}$ and $\mathrm{C}_{59} \mathrm{NH}$ and $\mathrm{C}_{60}$ on $[6,6]$-pyracylenic bonds.

\begin{tabular}{cccccc}
\hline [6,6]-bond & $\boldsymbol{\Delta} \mathbf{E}_{\mathbf{R C}}{ }^{\mathbf{a}}$ & $\boldsymbol{\Delta} \boldsymbol{E}^{\ddagger \mathbf{b}}$ & $\boldsymbol{\Delta} \mathbf{E}_{\mathbf{R}}^{\mathbf{c}}$ & $\boldsymbol{\Delta} \boldsymbol{\Delta} \boldsymbol{E}_{\mathbf{T S}} \mathbf{d}^{\mathbf{d}}$ & $\boldsymbol{\Delta} \mathbf{\Delta \mathbf { E } _ { \mathbf { R } } { } ^ { \mathbf { e } }}$ \\
\hline 1 & $-7.4(2.8)$ & $8.3(12.6)$ & $-19.9(-7.0)$ & $0.4(0.8)$ & $1.9(1.8)$ \\
2 & $-7.2(2.8)$ & $10.0(13.9)$ & $-16.8(-4.2)$ & $2.0(2.1)$ & $5.1(4.6)$ \\
$\mathbf{3}$ & $-7.9(\mathbf{1 . 8})$ & $\mathbf{8 . 0 ( 1 1 . 8 )}$ & $-\mathbf{2 1 . 8 ( - 8 . 8 )}$ & $\mathbf{0 . 0}(\mathbf{0 . 0})$ & $\mathbf{0 . 0}(\mathbf{0 . 0})$ \\
4 & $-6.4(3.2)$ & $10.1(14.7)$ & $-19.2(-6.5)$ & $2.1(2.9)$ & $2.6(2.3)$ \\
5 & $-7.1(3.0)$ & $9.2(13.4)$ & $-15.3(-2.7)$ & $1.2(1.5)$ & $6.5(6.1)$ \\
6 & $-7.4(2.9)$ & $8.5(12.7)$ & $-19.6(-6.7)$ & $0.5(0.9)$ & $2.2(2.0)$ \\
7 & $-6.4(3.3)$ & $11.6(16.3)$ & $-14.3(-1.8)$ & $3.6(4.4)$ & $2.2(7.0)$ \\
8 & $-6.8(3.2)$ & $9.6(14.1)$ & $-17.4(-4.7)$ & $1.6(2.2)$ & $7.5(4.1)$ \\
9 & $-7.3(2.6)$ & $8.2(13.4)$ & $-19.5(-6.8)$ & $0.2(0.5)$ & $4.5(2.0)$ \\
10 & $-7.2(2.9)$ & $8.9(13.1)$ & $-18.4(-5.7)$ & $0.9(1.2)$ & $2.3(3.1)$ \\
11 & $-6.6(3.3)$ & $11.0(15.6)$ & $-14.6(-2.1)$ & $3.0(3.8)$ & $7.2(6.7)$ \\
12 & $-7.2(2.9)$ & $8.4(12.6)$ & $-19.0(-6.3)$ & $0.4(0.7)$ & $2.8(2.5)$ \\
13 & $-7.0(3.1)$ & $9.2(13.6)$ & $-17.6(-5.1)$ & $1.2(1.7)$ & $4.2(3.7)$ \\
14 & $-7.2(2.8)$ & $8.4(12.7)$ & $-19.0(-6.3)$ & $0.4(0.9)$ & $2.8(2.5)$ \\
15 & $-7.0(3.0)$ & $8.9(13.3)$ & $-18.1(-5.5)$ & $0.9(1.5)$ & $3.7(3.3)$ \\
16 & $-7.2(2.9)$ & $9.4(13.8)$ & $-17.6(-4.9)$ & $1.5(2.0)$ & $4.2(3.9)$ \\
$\mathrm{C}_{60}{ }^{\mathrm{f}}$ & -7.1 & $5.2^{\mathrm{g}}$ & $-23.4^{\mathrm{g}}$ & & \\
\hline
\end{tabular}

${ }^{\mathrm{a}}$ Reactant complex (RC) energy: $\Delta E_{\mathrm{RC}}=E(\mathbf{R C})-E\left(\mathrm{C}_{59} \mathrm{NH}\right)-E(\mathrm{CP}){ }^{\mathrm{b}}$ Activation energy: $\Delta E^{\ddagger}=$ $\mathrm{E}(\mathbf{T S})-\mathrm{E}(\mathbf{R C}) .{ }^{\mathrm{c}}$ Reaction energy: $\Delta E_{\mathrm{R}}=E($ cycloadduct $)-E\left(\mathrm{C}_{59} \mathrm{NH}\right)-E(\mathrm{CP}) .{ }^{\mathrm{d}} \Delta \Delta E_{\mathrm{TS}}=\Delta E^{\ddagger}\left(\mathbf{T S}_{\mathbf{i}}\right)-$ $\Delta E^{\ddagger}$ (TS3). ${ }^{\mathrm{e}} \Delta \Delta E_{\mathrm{R}}=\Delta E_{\mathrm{R}}$ (bond i) $-\Delta E_{\mathrm{R}}$ (bond 3). ${ }^{\mathrm{f}}$ Data taken from reference 13a (computed at the same level of theory). ${ }^{\mathrm{g}}$ Experimental values of activation energy and reaction energy are 6.9 and -19.8 $\mathrm{kcal} / \mathrm{mol}$, respectively. ${ }^{16 \mathrm{a}}$

According to the data gathered in Table 1, the DA reaction with CP occurs preferentially, both kinetically and thermodynamically, on [6,6]-bond 3, which belongs to the six-membered ring where the nitrogen atom is present. ${ }^{17}$ Interestingly, the computed energies clearly indicate that the DA reactivity of the azafullerene $\mathrm{C}_{59} \mathrm{NH}$ is lower than that of $\mathrm{C}_{60}$, from both kinetic and thermodynamic points of view. ${ }^{18}$ This finding becomes evident when comparing the barrier and reaction energies computed for the process involving the $[6,6]$-bond 16 , i.e. the farthest bond to the nitrogen atom thus resembling the $[6,6]$-bond of $\mathrm{C}_{60}$, which are also higher than those computed for the process involving $\mathrm{C}_{60}$. This 
suggests that the heterocyclic ring in $\mathrm{C}_{59} \mathrm{NH}$ does not only strongly influence the rings close to it but also the entire fullerenic cage. It is also worthy to note that the regioselectivity of the DA in $\mathrm{C}_{59} \mathrm{NH}$ is expected to be low since there are four bonds $(1,6,9,14)$ with barriers less than $0.5 \mathrm{kcal} / \mathrm{mol}$ higher than the addition with the lowest energy barrier (3).

Although the reduced reactivity of $\mathrm{C}_{59} \mathrm{NH}$ may be initially related to the slight destabilization of the corresponding LUMO ( $-4.26 \mathrm{eV}$ vs $-4.20 \mathrm{eV}$, for $\mathrm{C}_{60}$ and $\mathrm{C}_{59} \mathrm{NH}$, respectively), the Activation Strain Model (ASM) ${ }^{11}$ of reactivity was applied next to gain a quantitative understanding into the origins of this reactivity trend. Within the ASM, also known as distortion/interaction model, ${ }^{19}$ the height of reaction barriers is described and understood in terms of the original reactants. Thus, the potential energy surface $\Delta E(\zeta)$ is decomposed, along the reaction coordinate $\zeta$, into the strain $\Delta E_{\text {strain }}(\zeta)$ associated with deforming the individual reactants from their equilibrium geometries plus the actual interaction $\Delta E_{\text {int }}(\zeta)$ between the deformed reactants (eq. 1$)$.

$$
\Delta E(\zeta)=\Delta E_{\text {strain }}(\zeta)+\Delta E_{\text {int }}(\zeta)
$$

Figure 2 illustrates the computed activation strain diagrams (ASD) for the cycloaddition reactions involving $\mathrm{CP}$ and $\mathrm{C}_{60}$ (solid lines) and $\mathrm{C}_{59} \mathrm{NH}$ (bond 3, dotted lines; bond 11, dashed lines) from the respective reactant complexes up to the corresponding transition states. The shape of the different curves is rather similar in both cases. Thus, the interaction energy between the deformed reactants, measured by the $\Delta E_{\text {int }}$ term, remains practically constant at the beginning of the reaction due to the onset of overlap and Pauli repulsion between the occupied $\pi$ orbitals on either of the reactants. Then, the $\Delta E_{\mathrm{int}}$ term inverts at a certain point along the reaction coordinate (i.e., at forming $\mathrm{C} \cdots \mathrm{C}$ distances of ca. 2.5 $\AA$ ) and becomes more and more stabilizing when reaching the corresponding transition state region. A similar behaviour was found in related DA reactions ${ }^{13,20}$ as well as in different types of pericyclic reactions. ${ }^{21}$ Nevertheless, the strong destabilizing effect of the deformation energy required to adopt the transition state geometry $\left(\Delta E_{\text {strain }}\right)$ overcomes the stabilization provided by the interaction term and therefore becomes the major factor controlling the activation barrier of the process. 




Figure 2. Comparative activation-strain diagrams for the Diels-Alder reactions between $\mathrm{CP}$ and $\mathrm{C}_{60}$ (solid lines), $\mathrm{C}_{59} \mathrm{NH}$ (bond 3, dotted lines) and $\mathrm{C}_{59} \mathrm{NH}$ (bond 7 , dashed lines) along the reaction coordinate projected onto the shortest forming $\mathrm{C} \cdots \mathrm{C}$ bond distance. All data have been computed at the ZORA-BP86-D3/TZ2P+//RI-BP86-D3/def2-SVP level.

Despite that, the strain energy is not the physical factor responsible for the different reactivity of $\mathrm{C}_{60}$ and $\mathrm{C}_{59} \mathrm{NH}$. As clearly seen in Figure 2, the computed strain term is rather similar for both cycloaddition reactions, and even less destabilizing for the less reactive azafullerene system at the transition state region. At variance, the interaction energy between the deformed reactants is markedly stronger for the reaction involving $\mathrm{C}_{60}$ as compared to $\mathrm{C}_{59} \mathrm{NH}$. Therefore, it can be concluded that the interaction energy constitutes the main factor governing the different reactivity of these fullerenes. For instance, at the same $\mathrm{C} \cdots \mathrm{C}$ forming distance of $2.3 \AA$, the difference in the interaction energy $\Delta \Delta E_{\mathrm{int}}=3.7 \mathrm{kcal} / \mathrm{mol}$ roughly matches the total energy difference between both transformations $(\Delta \Delta E=2.4 \mathrm{kcal} / \mathrm{mol})$. The major role of the interaction energy in the process becomes evident when considering the ASD for the reaction involving one of the least reactive [6,6]-bond of $\mathrm{C}_{59} \mathrm{NH}$ (bond 7, dashed lines in Figure 2). Indeed, for this particular reaction, the strain energy is nearly identical to that computed for the most reactive bond-3. However, the interaction energy between the deformed reactants is clearly weaker along the entire reaction coordinate, and as a result, the computed activation barrier for this process is much higher. 
Further quantitative insight into the factors making the interaction between the reactants weaker for the process involving the azafullerene system can be gained by means of the Energy Decomposition Analysis (EDA) method. ${ }^{12}$ Within this method, the $\Delta E_{\text {int }}$ term can be partitioned into meaningful energy contributions (eq. 2), namely the Pauli repulsion ( $\Delta E_{\text {Pauli, which comprises the destabilizing interactions }}$ between occupied orbitals), $\Delta V_{\text {elstat }}$ term (which corresponds to the classical electrostatic interaction between the unperturbed charge distributions of the deformed reactants), the orbital interaction $\left(\Delta E_{\text {orb}}\right.$, which accounts for charge transfer and polarization) and the $\Delta E_{\mathrm{disp}}$ term, which takes into account the interactions which are due to dispersion forces. Therefore:

$$
\Delta E_{\text {int }}(\zeta)=\Delta E_{\text {Pauli }}(\zeta)+\Delta V_{\text {elstat }}(\zeta)+\Delta E_{\text {orb }}(\zeta)+\Delta E_{\text {disp }}(\zeta)
$$

Figure 3 graphically shows the evolution of the different contributions to the total interaction energy for the cycloaddition reactions involving $\mathrm{C}_{60}$ (solid lines) and $\mathrm{C}_{59} \mathrm{NH}$ (bond 3, dotted lines) along the reaction coordinate. Despite the latter system benefits from a less destabilizing Pauli repulsion, particularly at the transition state region, the rest of attractive interactions are clearly stronger for the process involving the parent $\mathrm{C}_{60}$-fullerene. For instance, at the same $\mathrm{C} \cdots \mathrm{C}$ forming distance of $2.3 \AA$, the computed $\Delta V_{\text {elstat }}=-39.9 \mathrm{kcal} / \mathrm{mol}$ and $\Delta E_{\text {orb }}=-40.7 \mathrm{kcal} / \mathrm{mol}$ values for the reaction involving $\mathrm{C}_{59} \mathrm{NH}$ are comparatively lower (i.e. weaker) than the respective values computed for $\mathrm{C}_{60}\left(\Delta V_{\text {elstat }}=-\right.$ $47.5 \mathrm{kcal} / \mathrm{mol}$ and $\left.\Delta E_{\mathrm{orb}}=-53.0 \mathrm{kcal} / \mathrm{mol}\right)$. In addition, the latter system also benefits from stronger dispersion interactions, albeit to a much lesser extent $\left(\Delta \Delta E_{\text {disp }}=2.5 \mathrm{kcal} / \mathrm{mol}\right)$. Therefore, it can be concluded that the stronger interaction between the deformed reactants computed for the cycloaddition between $\mathrm{CP}$ and $\mathrm{C}_{60}$, which is translated into a lower activation barrier, finds its origin mainly in the stronger orbital and electrostatic interactions between the reactants practically along the entire reaction coordinate. 


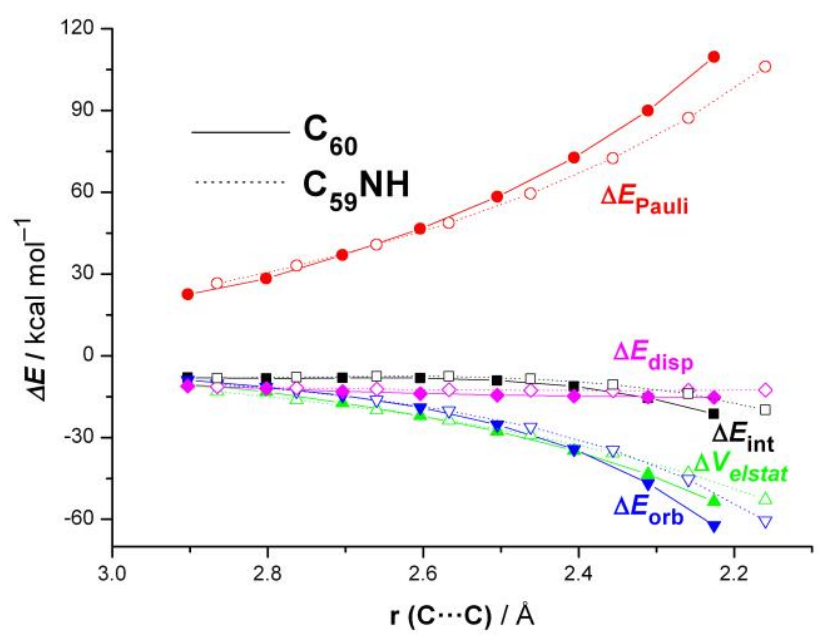

Figure 3. Decomposition of the interaction energy for the [4+2]-cycloaddition reactions between $\mathrm{CP}$ and $\mathrm{C}_{60}$ (solid lines) and $\mathrm{C}_{59} \mathrm{NH}$ (bond 3 , dotted lines) along the reaction coordinate projected onto the shortest forming $\mathrm{C} \cdots \mathrm{C}$ bond distance. All data have been computed at the ZORA-BP86-D3/TZ2P+//RIBP86-D3/def2-SVP level.

Finally, the origins of the stronger orbital interactions in $\mathrm{C}_{60}$ compared to the process involving its azafullerene counterpart can be also analyzed quantitatively by using the NOCV (Natural Orbital for Chemical Valence) extension of the EDA method. ${ }^{22}$ Thus, the EDA-NOCV approach, which provides pairwise energy contributions for each pair of interacting orbitals to the total bond energy, suggests that two main molecular orbital interactions dominate the total orbital interactions in these processes, namely the $\pi($ diene $) \rightarrow \pi^{*}($ fullerene $)$ and the reverse $\pi$ (fullerene) $\rightarrow \pi^{*}$ (diene) interactions (see Figure 4 , charge flow is red $\rightarrow$ blue). The former interaction is, as expected for a normal electronic demand DA process, clearly higher than the reverse interaction (i.e. $\left.\Delta E\left(\rho_{1}\right)>\Delta E\left(\rho_{2}\right)\right)$. Strikingly, both orbital interactions are clearly stronger for the process involving $\mathrm{C}_{60}$ than for $\mathrm{C}_{59} \mathrm{NH}$ (see Figure 4 for the interactions occurring at the same $\mathrm{C} \cdots \mathrm{C}$ distance of ca. $2.3 \AA$ ). Therefore, it can be concluded that the stronger orbital interactions in the parent $\mathrm{C}_{60}$-fullerene, which leads to an enhanced DA reactivity as compared to its azafullerene counterpart, derive mainly from a stronger $\pi$ (diene) $\rightarrow \pi^{*}($ fullerene) interaction but also, from stronger reverse $\pi($ fullerene $) \rightarrow \pi^{*}($ diene $)$, albeit to a much lesser extent. 
(a)


$\Delta E\left(\rho_{1}\right)=-28.8 \mathrm{kcal} / \mathrm{mol}$

$\Delta E\left(\rho_{2}\right)=-12.0 \mathrm{kcal} / \mathrm{mol}$



$\Delta E\left(\rho_{1}\right)=-22.6 \mathrm{kcal} / \mathrm{mol}$

Figure 4. Plot of the deformation densities $(\Delta \rho \square \square \square$ of the pairwise orbital interactions between $\mathrm{CP}$ and $\mathrm{C}_{60}$ (a) and $\mathrm{C}_{59} \mathrm{NH}$ (b) and associated stabilization energies $(\Delta E$, in $\mathrm{kcal} / \mathrm{mol})$. The color code of the charge flow is red $\rightarrow$ blue.

In conclusion, we have computationally analyzed the factors controlling the DA reactivity of $\mathrm{C}_{59} \mathrm{NH}-$ azafullerene in comparison with the parent $\mathrm{C}_{60}$-fullerene. Besides predicting the regioselectivity of the transformation, the reduced reactivity of the $\mathrm{C}_{59} \mathrm{NH}$ system has been quantitatively analyzed in detail. It is found that the presence of the nitrogen atom and the $\mathrm{CH}$ fragment in the fullerene strongly modifies the nature of the cage in the sense that the interaction between the deformed reactants along the reaction coordinate is remarkably reduced. This weaker interaction is mainly the result of weaker electrostatic and orbital interactions, the latter coming mainly from a lower $\pi$ (diene) $\rightarrow \pi^{*}$ (fullerene) interaction. We believe that the insight gained in this study will guide further experimental developments in the less explored chemistry of heterofullerenes. 
Supporting Information Available. Figures S1 and S2 (showing the computed profile involving the most reactive bond of $\mathrm{C}_{59} \mathrm{~N}$ ), Computational Details and Cartesian coordinates and energies of all species discussed in the text. This material is available free of charge via the Internet at http://pubs.acs.org.

\section{AUTHOR INFORMATION}

\section{Corresponding Authors}

* E-mail: $\underline{\text { israel@quim.ucm.es }}$

\section{Notes}

The authors declare no competing financial interest.

\section{ACKNOWLEDGMENTS}

We are grateful for financial support from the Spanish MINECO-FEDER (Grants CTQ2013-44303-P, CTQ2016-78205-P and CTQ2014-51912-REDC to I. F. and CTQ2014-54306-P to M. S.), Fundación BBVA (Convocatoria 2015 de Ayudas Fundación BBVA a Investigadores y Creadores Culturales), and Catalan DIUE (projects 2014SGR931, ICREA Academia 2014 prize, and XRQTC to M. S.). The FEDER grant UNGI10-4E-801 has also funded this research. Y. G.-R. acknowledges the MINECO for a FPI grant.

\section{References and Notes}

1. (a) Fullerenes: From Synthesis to Optoelectronic Properties (Eds.: D. M. Guldi, N. Martín), Kluwer, Dordrecht, 2002. (b) Fullerenes. Principles and Applications (Eds.: F. Langa, J.-F. Nierengarten), RSC, Cambridge, 2011. (c) Martín, N. Chem. Commun. 2006, 2093.

2. Kroto, H. W.; Heath, J. R.; O’Brien, S. C.; Curl R. F.; Smalley, R. E. Nature 1985, 318, 162.

3. Hirsch, A.; Bettreich, M. in Fullerenes, Chemistry and Reactions, Wiley-VCH, Weinheim, 2005. 
4. Vostrowsky, O.; Hirsch, A. Chem. Rev. 2006, 106, 5191.

5. (a) Hummelen, J. C.; Knight, B.; Pavlovich, J.; González, R.; Wudl, F. Science 1995, 269, 1554. (b)

Nuber, B.; Hirsch, A. Chem. Commun. 1996, 1421.

6. Hashikawa, Y.; Murata, M.; Wakamiya, A.; Murata, Y. J. Am. Chem. Soc. 2016, 138, 4096.

7. (a) Keshavarz-K, M.; González, R.; Hicks, R. G.; Srdanov, G.; Srdanov, V. I.; Collins, T. G.; Hummelen, J. C.; Bellavia-Lund, C.; Pavlovich, J.; Wudl, F.; Holczer, K. Nature 1996, 383, 147. (b) Xin, N.; Huang, H.; Zhang, J.; Dai, Z.; Gan, L. Angew. Chem. Int. Ed. 2012, 51, 6163. For a recent review, see (c) Rotas, G.; Tagmatarchis, N. Chem. Eur. J. 2016, 22, 1206.

8. (a) Zhang, G.; Huang, S.; Xiao, Z.; Chen, Q.; Gan, L.; Wang, Z. J. Am. Chem. Soc. 2008, 130, 12614.

(b) Neubauer, R.; Heinemann, F. W.; Hampel, F.; Rubin, Y.; Hirsch, A. Angew. Chem. Int. Ed. 2012, $51,11722$.

9. (a) Martin-Gomis, L.; Rotas, G.; Okhubo, K.; Fernández-Lazaro, F.; Fukuzumi, S.; Tagmatarchis, N.; Sastre-Santos, A. Nanoscale 2015, 7, 7437. (b) Rotas, G.; Charalambidis, G.; Glatzl, L.; Gryko, D. T.; Kahnt, A.; Coutsolelos, A. G.; Tagmatarchis, N. Chem. Commun. 2013, 49, 9128.

10. Representative examples: (a) Osuna, S.; Swart, M.; Solà, M. Chem. Eur. J. 2009, 15, 13111 (b) Garcia-Borràs, M.; Osuna, S.; Luis, J. M.; Swart, M.; Solà, M. Chem. Eur. J. 2012, 18, 7141. (c) GarciaBorràs, M.; Osuna, S.; Swart, M.; Luis, J. M.; Solà, M. Chem. Commun. 2013, 49, 1220.

11. For recent reviews, see: (a) Fernández, I.; Bickelhaupt, F. M. Chem. Soc. Rev. 2014, 43, 4953. (b) Wolters, L. P.; Bickelhaupt, F. M. WIREs Comput. Mol. Sci. 2015, 5, 324

12. von Hopffgarten, M.; Frenking, G. WIREs Comput. Mol. Sci. 2012, 2, 43 and references therein.

13. (a) Fernández, I.; Solà, M.; Bickelhaupt, F. M. Chem. Eur. J. 2013, 19, 7416. (b) Fernández, I.; Solà, M.; Bickelhaupt, F. M. J. Chem. Theory Comput. 2014, 10, 3863. (c) Bickelhaupt, F. M.; Solà, M.; 
Fernández, I. Chem. Eur. J. 2015, 21, 5760. (d) García-Rodeja, Y.; Solà, M.; Bickelhaupt, F. M.; Fernández, I. Chem. Eur. J. 2016, 22, 1368. (e) García-Rodeja, Y.; Solà, M.; Fernández, I. Chem. Eur. J. 2016, 22, 10572.

14. For very recent studies: (a) Lou, N.; Li, Y.; Cui, C.; Liu, Y.; Gan, L. Org. Lett. 2016, 18, 2236. (b) Eigler, R.; Heinemann, F. W.; Hirsch, A. Chem. Eur. J. 2016, 22, 13575.

15. All calculations were carried out at the ZORA-BP86-D3/TZ2P+//RI-BP86-D3/def2-SVP level. This level was chosen because it was confirmed to provide accurate activation and reaction energies for the parent cycloaddition between $\mathrm{C}_{60}$ and cyclopentadiene (see references 13a and 16). See Computational Details in the Supporting Information.

16. (a) Osuna, S.; Swart, M.; Solà, M. J. Phys. Chem. A 2011, 115, 3491. (b) Garcia-Borràs, M.; Luis, J. M.; Swart, M.; Solà, M. Chem. Eur. J. 2013, 19, 4468.

17. Calculations in the presence of toluene as solvent indicate that the solvent effect in this process is negligible $\left(\Delta E^{\ddagger}=7.7 \mathrm{kcal} / \mathrm{mol}\right.$ and $\left.\Delta E_{\mathrm{R}}=-21.1 \mathrm{kcal} / \mathrm{mol}\right)$.

18. A similar result was found previously by using much less accurate AM1 calculations. However, the predicted regioselectivity is completely different. See: Liang, Y.; Shang, Z; Xu, X.; Zhao, X. Acta Phys. -Chim. Sin. 2008, 24, 1811.

19. (a) Ess, D. H.; Houk, K. N. J. Am. Chem. Soc. 2007, 129, 10646. (b) Ess, D. H.; Houk, K. N. J. Am. Chem. Soc. 2008, 130, 10187. (c) Medina, J. M.; Mackey, J. L.; Garg, N. K.; Houk, K. N. J. Am. Chem. Soc. 2014, 136, 15798.

20. (a) Fernández, I.; Bickelhaupt, F. M. J. Comput. Chem. 2014, 35, 371. (b) García-Rodeja, Y.; Fernández, I. J. Org. Chem. 2016, 81, 6554.

21. (a) Fernández, I.; Bickelhaupt, F. M.; Cossío, F. P. Chem. Eur. J. 2009, 15, 13022. (b) Fernández, I.; Cossío, F. P.; Bickelhaupt, F. M. J. Org. Chem. 2011, 76, 2310. (c) Fernández, I.; Bickelhaupt, F. M.; 
Cossío, F. P. Chem. Eur. J. 2012, 18, 12395. (d) Fernández, I.; Bickelhaupt, F. M.; Cossío, F. P. Chem. Eur. J. 2014, 20, 10791. (e) Fernández, I. Phys. Chem. Chem. Phys. 2014, 16, 7662. (f) Fernández, I.; P. Cossío, F. P. J. Comput. Chem. 2016, 37, 1265.

22. Mitoraj, M. P.; Michalak, A.; Ziegler, T. J. Chem. Theory Comput. 2009, 5, 962. 